\title{
The correlation between microstructure and thermomechanical properties studied on AlCuMg-based alloys
}

\author{
U. SCHMIDT and R. UNGER \\ Martin Luther University of Halle-Wittenberg, Department of Physics, 06099 Halle, Germany
}

\begin{abstract}
This paper deals with the description of the structure and precipitation sequence of AlCu 4.5 alloys with a content of $\mathrm{Mg}$ between those of binary $\mathrm{AlCu}$ and quasi-binary AlCuMg alloys. For alloys with a small Mg content (0.23 wt\%) these are the coherent $\mathrm{Cu}-1$ ike GP zones and the incoherent $\boldsymbol{\theta}^{\prime}$ and $\boldsymbol{\theta}$ phases with the adequate content of dissolved $\mathrm{Mg}$, so the precipitation sequence can be essentially realized without any difficulties. In the case of higher $\mathrm{Mg}$ concentration a re-orientation occurs because it requires both time and energy. An undisturbed transition to the $\boldsymbol{\theta}(\mathrm{Mg})$ phase is impossible. The phase structure becomes more similar to that of the $S$ phase but it is not safe to say that it is already a quasi-binary structure. The different size developments between the AlCu4.5 and AlCuMg0.98 alloys are discussed.
\end{abstract}

\section{Introduction}

Since many years the binary $\mathrm{AlCu}$ alloy has been investigated in the whole sequence range. As a result a variety of forms of the Guinier-Preston (GP) zones was found [1].

The stability of the GP zones and the metastable phases depends on the preageing conditions. This result could be confirmed by extensive investigations of the partial and total reversion.

In many production processes magnesium $(\mathrm{Mg})$ is added to the AlCu alloys because magnesium improves the room-temperature (RT) hardening of technical AlCu alloys. But up to now the exact mechanism of the formation of the CuMg complexes is not completely known.

Above all the question is in the dark whether different types of GP zones do exist for AICuMg-alloys.

The investigations of one-step ageing show a different influence depending on the Mg concentration.

Reversion experiments give special information on the stability of the metastable precipitates.

The TTU diagram as a sumary result of the one-step ageing (see Fig.1):

- Magnesium accelerates the decomposition.

- The possibility of heterogeneous nucleation of semicoherent precipitates in needle form on helical dislocations and dislocation loops accelerate the decomposition of the AlCuMg-alloys [2]. 
- Dislocations in Al alloys are not favoured in the usual a/2 [110] direction but in the $a / 2$ [001] direction.

- Investigations of the earlier states of decomposition in AlCu4.5MgX support the occurrence of greater precipitation density and more fine-disperse precipitates as compared to the binary AlCu alloy.

- The form multiplicity of GP zones, which is characteristic of the binary $A l C u$ alloys, is missing in AlCuMg alloys since the thickening is important to the size growth (in AlCu alloys the precipitates have a disk form whereas those of the AlcuMg alloys are cylindricall.

- It is uninteligible in the frame of the acceleration and continuous insertion of $\mathrm{Mg}$ in the $\mathrm{Cu}-\mathrm{GP}$ zones that stable phase lines, homogeneity, solvus, and liquid lines and the eutectical temperature occur, and that these lines abruptly transform into those of the quasi-binary alloys (see Fig.2).

\section{Experimental}

Positron-annihilation lifetime technique, differential thermoanalysis, and scanning electron-microscopy complete the set of methods such as Vicker's hardness, neutron small-angle scattering and transmission electron-microscopy because they are expedient to follow up the decomposition kinetics at higher temperatures (Table 1 ).

Four alloys were investigated with almost equal $\mathrm{Cu}$ but varying $\mathrm{Mg}$ contents between 0 and 0.98 wt: produced from material of $4 \mathrm{~N}$ purity (Table 2). The samples were homogenized at $500{ }^{\circ} \mathrm{C}$ for $8 \mathrm{~h}$, then IQ-quenched into water, and isothermally or isochronally aged at the annealing temperature $\mathrm{T}_{\mathrm{a}}$ for a time $t_{\mathrm{a}}$.

\section{Results and Discussion}

\subsection{Thermal Analysis}

The A0.0 alloy (Fig.3) essentially shows the complete precipitation sequence, ie, both formation and dissolution. The next stable phase can only be formed after the dissolution of the previous phase. In particular, in the case of the GP-zone interval, the dissolution takes place in a fixed small region. This is in conformity with former results which describe that a definite state (type and size of a GP zone, precipitated $\mathrm{Cu}$ content) possesses a definite solvus temperature. In contrast to that, the formation and dissolution of $\theta^{\prime}$ and $\theta^{\prime}$ phases take place in a wide temperature interval. The $\boldsymbol{\theta}$ phase is already formed during the partial dissolution of the $\theta$ i phase.

In the case of the $A 0.23$ alioy the formation of the $\theta(\mathrm{Mg})$ phase provides the partial dissolution of the $\theta^{\prime}(\mathrm{Mg})$ phase. The formation of the semicoherent $\theta^{\prime}(\mathrm{Mg})$ phase is more intensive than in an $\mathrm{AlCu}$ alloy. The plot of the A0.56 alloy shows a further intensification of the formation of the $\theta$ ' phase and a decrease in its dissolution before the transition to the stable $\boldsymbol{\theta}(\mathrm{Mg})$ phase.

The evolution of the dissolution peak at $\mathrm{T}=227{ }^{\circ} \mathrm{C}$ is noteworthy.

The heat flow of the dissolution peak is very great for the $\mathrm{A} 0.98$ alloy. The subsequent formation enthalpy at $\mathrm{T}=295{ }^{\circ} \mathrm{C}$ exceeds all enthalpies realized. A wide dissolution interval follows, which shows the transition to the homogeneous dissolution.

The cooling trace show a formation maximum at $210{ }^{\circ} \mathrm{C}$ which can already be taken from the plot of the A0.56 alloy. The cause of this formation process can only be $\mathrm{Cu}$ and $\mathrm{Mg}$ atoms dissolved, respectively, which could 
not be completely precipitated because of the high cooling rate. With respect to the precipitation sequence the formation of GP zones should be essential. This result supports the fact that the transition to semicoherent and incoherent precipitates, respectively, is more difficult on the way of homogeneous nucleation.

\subsection{Hardness measurements}

\subsubsection{Hardening curves after isothermal annealing}

In the case of the $\mathrm{A} 0.98$ alloy in the interval from 130 to $300{ }^{\circ} \mathrm{C}$, the isothermal hardening shows the transition to the semicoherent phase at $190{ }^{\circ} \mathrm{C}$ which is indicated by the HV-hardness maximum. The shift of this maximum at higher temperatures to shorter times is connected with the acceleration of the hardening process at higher temperatures (see Fig. 4).

The HV-hardness maximum is missing for all alloys in the annealing temperature interval from 350 to $410^{\circ} \mathrm{C}$. The indirect state quenched in at $\mathrm{T}_{\mathrm{a}}$ directly approaches a plateau with almost the same value for all alloys. Differences can only be taken from the length of this plateau. Only in the AlCu alloy such a plateau could not be found which shows a transition to the $\boldsymbol{\theta}$ phase. This differentiation becomes more distinct at the annealing temperature $\mathrm{T}_{\mathrm{a}}=410^{\circ} \mathrm{C}$.

The comparison of these results with those of SEM investigations indirectly confirms this statement. Within the plateau essential transition processes take place that cannot be characterized as $\boldsymbol{\theta}$ phase in the A0.98 alloy at $350^{\circ} \mathrm{C}$. In the $\mathrm{AO} .0$ alloy the HV hardness continuously decreases which supports the assumption that the transition to the $\boldsymbol{\theta}$ phase takes place without any nucleation hindrances.

\subsubsection{Hardening curves after isochronal annealing}

The isochronal HV-hardness measurements that were parallely performed with the positron-annihilation lifetime measurements show no essential differences from expectations up to $\mathrm{T}_{\mathrm{a}}=200{ }^{\circ} \mathrm{C}$. (The procedures for both techniques were the same: the samples were heated step by step, see also Fig.5). The HV maximum is insignificantly shifted to higher values with increasing $\mathrm{Mg}$ content which is connected with the higher thermal stability of $\mathrm{Mg}$-containing GP zones and $\theta^{\prime \prime}$ precipitates already mentioned. The $H V$ decrease for $T_{a}$ greater than $200{ }^{\circ} \mathrm{C}$ is a typical indication of the coarsening and coherence break of the precipitates.

However, the HV courses above $\mathrm{T}_{\mathrm{a}}=350^{\circ} \mathrm{C}$ are important.

The indicated plateau in the A0.0 alloy (small hardness contribution) should originate from the transformation of the $\boldsymbol{\theta}^{\prime}$ precipitates. The copper is precipitated in relatively small incoherent phases. The decrease in the HV hardness to the as-quenched state and the re-increase are caused by coarse incoherent $\theta$ phases $\left(\mathrm{Al}_{2} \mathrm{Cu}\right)$ and the beginning homogenization (dissolution of copper in the matrix) and starting decomposition after the quenching into water.

The Mg-containing AlCu alloys show a quick HV-hardness decrease with rising temperature up to $350^{\circ} \mathrm{C}$, too. After an intermediate weak reversion a new HV-hardness increase follows, which is more distinct in case of the higher $\mathrm{Mg}$ content. After fast reaching the as-quenched state the homogenization and re-hardening (increase of HV-hardness) start then, too.

\subsection{Positron-lifetime measurements}

The results of positron-lifetime measurements are shown in Fig. 6. The results can be interpreted as follows, starting from the simplified statement that the decrease in the lifetime characterizes a coarsening or 
a dissolution process and that the increase in lifetime is caused by a formation process.

At first for all alloys a coarsening process of the GP zones takes place. The lifetimes decrease to values that correspond to the complete reversion of the GP zones. The estimated average lifetimes for the complete solubility of the $A 0.98$ alloy $(\tau=164 \mathrm{ps})$ do not essentially differ from that of the binary $\mathrm{A} 0.0$ alloy $(\tau=165 \mathrm{ps})$. If the vacancy foreign-atom mechanism is used, for the binary $\mathrm{AlCu}$ alloy a lifetime of $\tau=210 \mathrm{ps}$ and for the quasi-binary AlCuMg alloy a lifetime of $\tau=221$ ps can be calculated.

The Mg contents of the $A 0.23$ and $A 0.56$ alloys shift the solvus lines somewhat to higher temperatures. The formation of the $\boldsymbol{\theta}^{\prime \prime}$ precipitates follows. A higher $\mathrm{Mg}$ content accelerates this process and the process starts at lower temperatures. The coarsening of the $\theta^{\prime \prime}$ precipitates is characterized by the decrease in the average lifetime, again. The second minimum is differentiated. An increasing $\mathrm{Mg}$ content shifts this minimum to lower temperatures.

From the course of the average lifetime can be learned that the vacancies anneal out at a high rate.

The smaller decrease of the average lifetime for the A0.98 alloy in the region of the minima is connected with the higher thermal stability of vacancy loops. This result is an indication of a changed decomposition behaviour in the A0.98 alloy, too. It is not unambiguous if a change in the decomposition mechanism occurs.

\subsection{Scanning electron-microscopy (SEM) investigations}

Scanning electron-microscopic photographs confirm the continuous growth of inhomogeneous precipitates between 300 and $450{ }^{\circ} \mathrm{C}$. At a temperature of $300{ }^{\circ} \mathrm{C}$ no analysable precipitates could be found because of the low SEM contrast. Only when the phases have distinct incoherent structures, then they can be displayed by SEM.

Fig. 7 shows the evolution of the diameter and the particle density. There is a high precipitation density for the $A 0.0$ alloy at $\mathrm{T}_{a}=350^{\circ} \mathrm{C}$.

In the A0.98 alloy a reversion minimum can be found at $\mathrm{T}_{\mathrm{a}}=350^{\circ} \mathrm{C}$ and $t_{a}=50 \mathrm{~min}$. No precipitates are evident. The formation of $\theta$ starts at $t_{\mathrm{a}}=100 \mathrm{~min}$ and is in full progress at $\mathrm{T}_{\mathrm{a}}=410^{\circ} \mathrm{C}$.

The decomposition can be described by three stages: nucleation, growth, and ostwald ripening. In particular, the growth and ostwald ripening are important to the investigated temperature and time region. For the "classical" description the LSW (Lifshitz, slyozov, Wagner) theory is used predominantly.

Now the present experimental results are analyzed with respect to the phase growth (see Figure).

In the A0.0 alloy the size growth can be described using a $d^{3}$ law. At the temperature $\mathrm{T}_{\mathrm{a}}=410{ }^{\circ} \mathrm{C}$ the validity of the $\mathrm{d}^{3}$ law is restricted to the beginning. Beginning from $t_{a}=200$ min it seems that only Ostwald ripening occurs. The decrease in the precipitation density for $\mathrm{T}_{a}=350{ }^{\circ} \mathrm{C}$ means $a$ growth on the basis of the destruction of smaller precipitates (thermodynamic process). The strong decrease in the particle density at $\mathrm{T}_{\mathrm{a}}=$ $410^{\circ} \mathrm{C}$ is unintelligible at first glance. Considering the small size change, this decrease can only be understood as the transition to the $\theta$ phase and the considerable increase in the Cu solubility in the $\mathrm{Al}$ matrix (increase to 1.5 wto).

The $\mathrm{Mg}$ has an influence on the growth behaviour, too. At $\mathrm{T}_{\mathrm{a}}=350{ }^{\circ} \mathrm{C}$ the growth actually belongs to the $\mathrm{d}^{3}$ law, but the Mg distinctly influences the growth in the case of annealing at $\mathrm{T}_{\mathrm{a}}=410{ }^{\circ} \mathrm{C}$.

considering the $\mathrm{A} 0.23$ alloy, the ostwald ripening is shifted to smaller 
annealing times (at $\mathrm{T}_{\mathrm{a}}=410{ }^{\circ} \mathrm{C}$ and $\mathrm{t}_{\mathrm{a}}=50 \mathrm{~min}$ ). This result agrees with the hardness course (HV-hardness decrease above $50 \mathrm{~min}$ as compared to the A0.0 alloy with the beginning at $t_{a}=200 \mathrm{~min}$ ).

In the case of the $A 0.56$ alloy, the $d^{3}$ relationship is valid in effect for $T_{a}=410{ }^{\circ} \mathrm{C}$ but higher d values are observed as compared to $T_{a}=350{ }^{\circ} \mathrm{C}$. We can take the continuity of the nucleation as the basis.

The $\mathrm{d}^{3}$ law is valid for the $\mathrm{A} 0.98$ alloy at $\mathrm{T}_{\mathrm{a}}=350{ }^{\circ} \mathrm{C}$, too. The particle density increases very fast. The formation is distinct. First of all, at $\mathrm{T}_{\mathrm{a}}=410{ }^{\circ} \mathrm{C}$ a growth occurs at shorter times, too, but slower as compared to the $\mathrm{d}^{3}$ relation. The decrease in the particle density refers to a growth at the expense of the smaller particles.

But it is necessary to consider the temperature-dependent solubility of $\mathrm{Cu}$ and $\mathrm{Mg}$ in the Al matrix. That is to say that the $\mathrm{Mg}$ decreases the $\mathrm{Cu}$ solubility in the Al matrix at $350{ }^{\circ} \mathrm{C}$ from 0,85 wt\% to 0.7 wt\% and at $410{ }^{\circ} \mathrm{C}$ from 1.5 wt: to 1 wt\%, respectively. That means that more $\mathrm{Cu}$ is proportionally available in the precipitates. The precipitation density slowly decreases or keeps constant. This fact is valid for both the A0.23 and $A 0.56$ alloys. Only in case of the $A 0.98$ alloy the process begins to reverse since the precipitates coarsen considerably faster.

The size distribution was analyzed to check this statement.

- The higher the concentration the narrower the size distribution.

- The higher the temperature the earlier the precipitation begins.

These statements are valid for the A0.0, A0.23, and A0.56 alloys. The A0.98 alloy is an exception to the rule, too.

The investigations of the decomposition behaviour of Al-Cu4.5Mg-Mg(X) up to the homogenization region show:

- Mg influences the precipitation sequence.

- There could not be found any indications of different coexisting precipitation structures like $\mathrm{Mg}$-containing and $\mathrm{Mg}$-free precipitations in the case of the $\mathrm{Cu}-\mathrm{Mg}$ ratio $>2: 1$.

- The decomposition behaviour of the A0.56 and A0.98 alloys distinctly differs from that of the binary AlCu alloys in the region of the $\theta^{\prime}$ and $\theta$ phases. The A0.98 alloy most distinctly shows this influence. A strong phase reformation above $300^{\circ} \mathrm{C}$ occurs depending on the decomposition rate (thermal analysis, isochronal hardness traces, positron lifetimes). The formation of the stable phase starts only above $350{ }^{\circ} \mathrm{C}$ in the case of the A0.98 alloy (SEM).

\section{Conclusions}

Alloys with a content of $\mathrm{Mg}$ which diverge from those of the quasi-binary composition have structures between those of binary $\mathrm{AlCu}$ and quasi-binary Alcumg alloys. They take the energetically favourable structures.

For alloys with a small Mg content (A0.23 alloy) these are the coherent $\mathrm{Cu}$-like GP zones and the incoherent $\boldsymbol{\theta}^{\prime}$ and $\boldsymbol{\theta}$ phases with the adequate content of dissolved $\mathrm{Mg}$, so the precipitation sequence can be essentially realized without any difficulties. In the case of the higher Mg concentration a re-orientation occurs according to the results of this paper. This re-orientation requires both time and energy. An undisturbed transition to the $\boldsymbol{\theta}(\mathrm{Mg})$ phase is impossible. The phase structure becomes more similar to that of the $S$ phase. It is not safe to say that it is already a quasi-binary structure. Further investigations are necessary. The different size developments between the A0.0 and A0.98 alloys and the strong reversion and reformation in the range above $300^{\circ} \mathrm{C}$ can be interpreted in this way.

\section{References}

[1] SCHÜLBE R., SCHMIDT U., phys. stat. sol. (a) 103 (1987) 29,

[2] PRATSCHLER H.-CH., SCHMIDT U., SCHUULBE R., SIEBERT P., phys. stat. sol. (a) 125 (1991) 417 . 


\section{Tables}

Table 1: Measurement Methods

\begin{tabular}{||l|l|l|l||}
\hline Method & Device & Measurement & Remarks \\
\hline Calorimetry & $\begin{array}{l}\text { DSC 7 (Perkin Elmer } \\
\text { Corp) }\end{array}$ & $\begin{array}{l}\text { Heating and cooling rates 20 } \\
\text { and 40 K/min }\end{array}$ & $\begin{array}{l}\text { uncertainty 0.3 } \mathrm{K}, \\
\text { sample weight 20 -25mg }\end{array}$ \\
\hline $\begin{array}{l}\text { Positronen-lifetime } \\
\text { measurement }\end{array}$ & EG\&G ORTEC & $\begin{array}{l}\text { conventional fast-slow } \\
\text { coincidence }\end{array}$ & time resolution230 ps \\
\hline $\begin{array}{l}\text { Scanning electron- } \\
\text { microscopy }\end{array}$ & $\begin{array}{l}\text { BS 300, Tesla, Picture } \\
\text { analysis system } \\
\text { BAS-Robotron }\end{array}$ & $\begin{array}{l}\text { characteristic size } \\
\text { distribution and } \\
\text { particle size }\end{array}$ & $\begin{array}{l}\text { diameter of a circle equal in size and } \\
\text { statistic size distribution }\end{array}$ \\
\hline HV-Measurement & $\begin{array}{l}\text { Neophot II, Hanemann } \\
\text { mikrohardness }\end{array}$ & $\begin{array}{l}\text { HV measurment, isothermal } \\
\text { and isochronal annealing }\end{array}$ & $\begin{array}{l}\text { Power: 0.102 N, measurement at room } \\
\text { temperature }\end{array}$ \\
\hline
\end{tabular}

Tab. 2 : Cu- and Mg-Contents of the AlCuMg-Allovs

\begin{tabular}{|c|c|c|}
\hline Alioy & $\mathrm{c}_{\mathrm{cu}} / \mathrm{wt} \%$ & $\mathrm{c}_{\mathrm{Mg}} / \mathrm{wt} \%$ \\
\hline $\mathrm{A} 0.0$ & 4.5 & - \\
\hline $\mathrm{A} 0.23$ & 4.5 & .23 \\
\hline $\mathrm{A} 0.56$ & 4.5 & .56 \\
\hline $\mathrm{A} 0.67$ & 4.5 & .67 \\
\hline $\mathrm{A} 0.98$ & 4.5 & .98 \\
\hline
\end{tabular}

\section{Figure Captions}

Fig.1: TTU diagram of one-step ageing ( $T_{a}$ : ageing temperature, $t_{p}$ : ageing time at the plateau beginning)

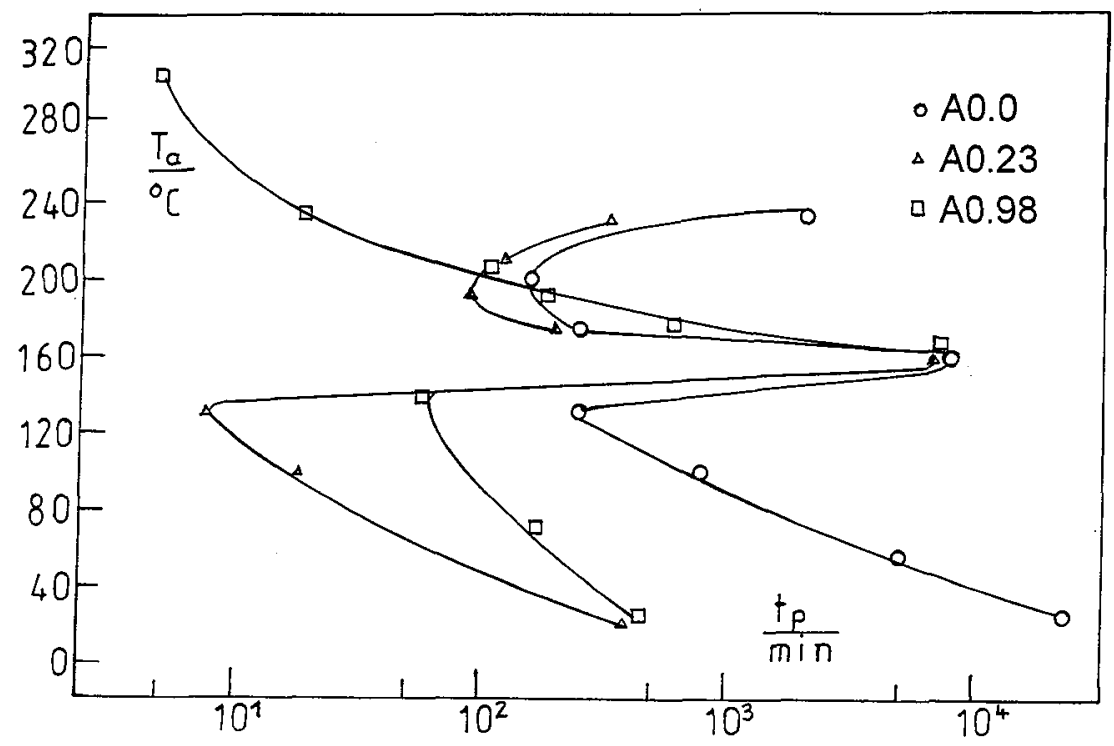


Fig.2: The stable phase lines of AlCu4.5Mg alloys depending on the Mg concentration
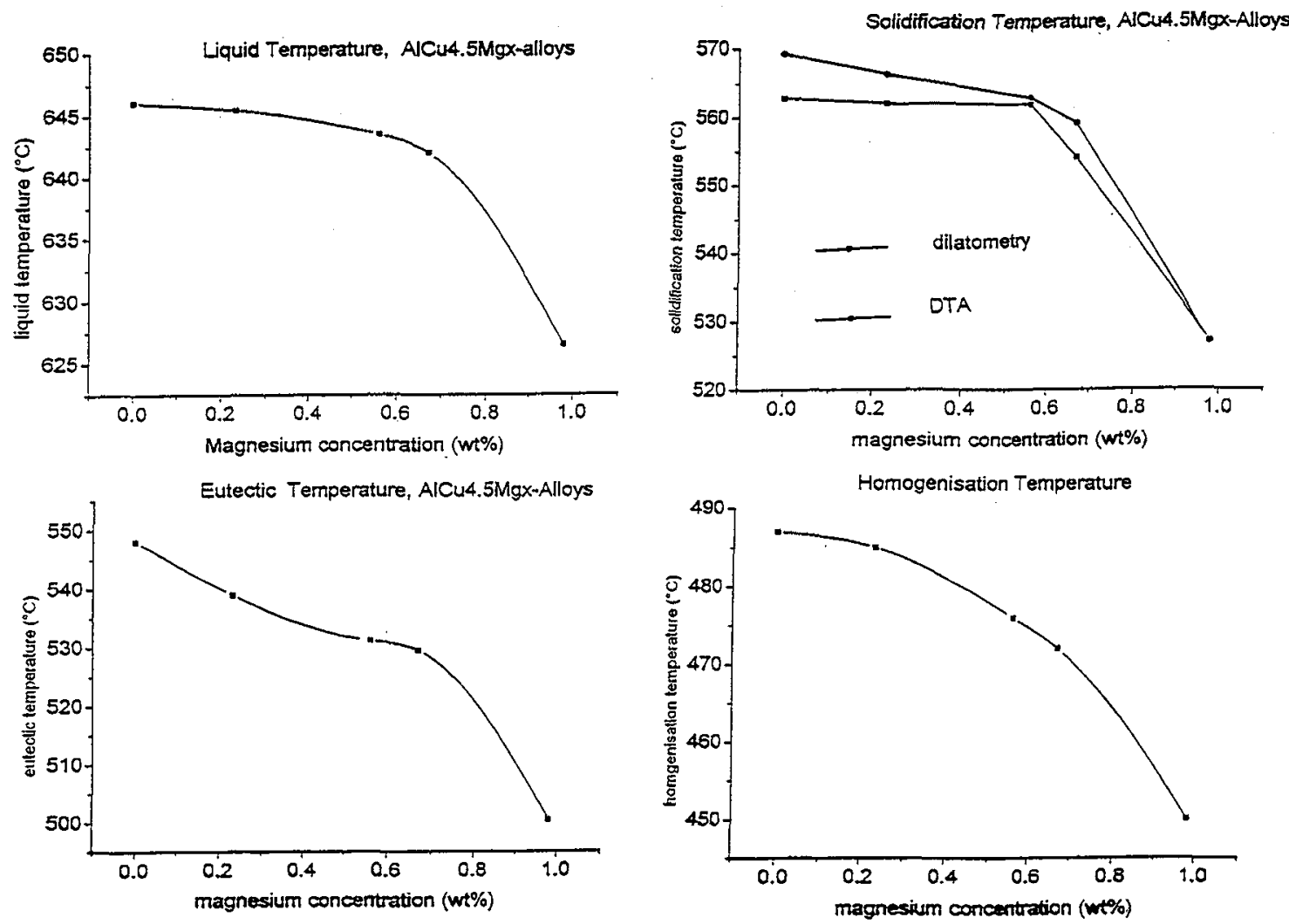

Fig.3: DSC heating traces after water quenching from $\mathrm{T}_{\mathrm{q}}=500^{\circ} \mathrm{C}_{r} \mathrm{t}_{\mathrm{q}}=$ $8 \mathrm{~h}$

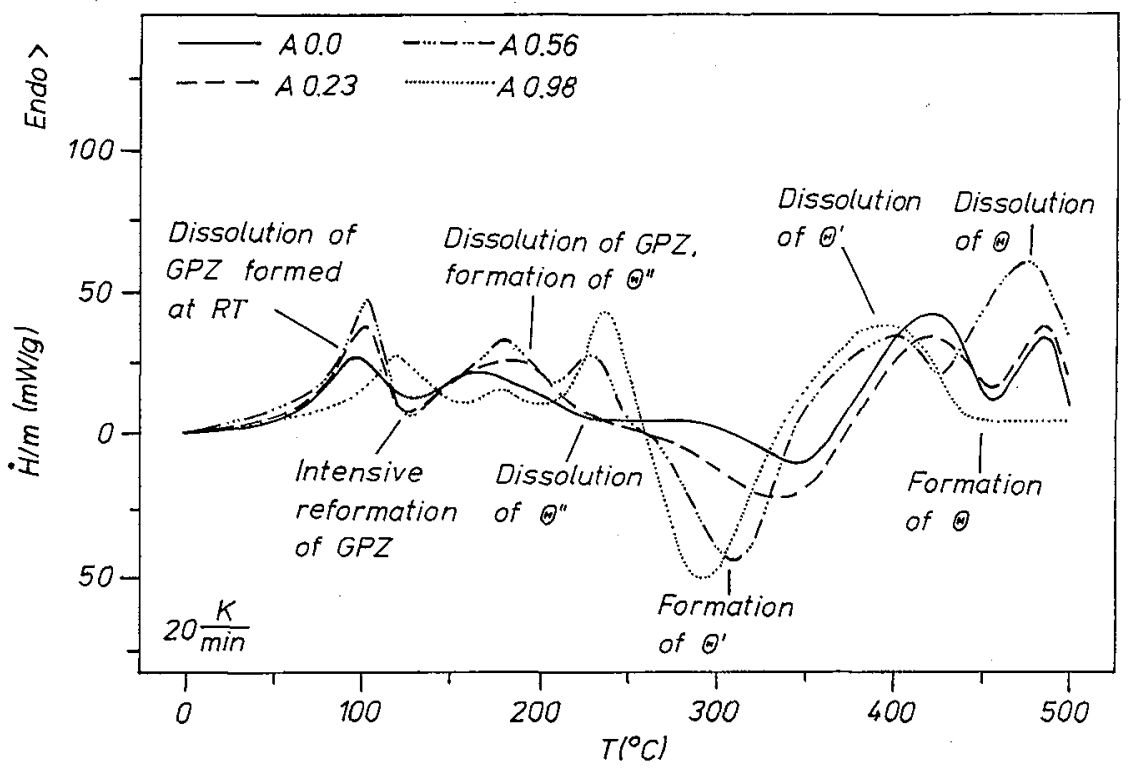


Fig.4: Vickers' hardness after isothermal annealing of the A0.98 alloy between $\mathrm{T}_{\mathrm{a}}=130^{\circ} \mathrm{C}$ and $350^{\circ} \mathrm{C}$

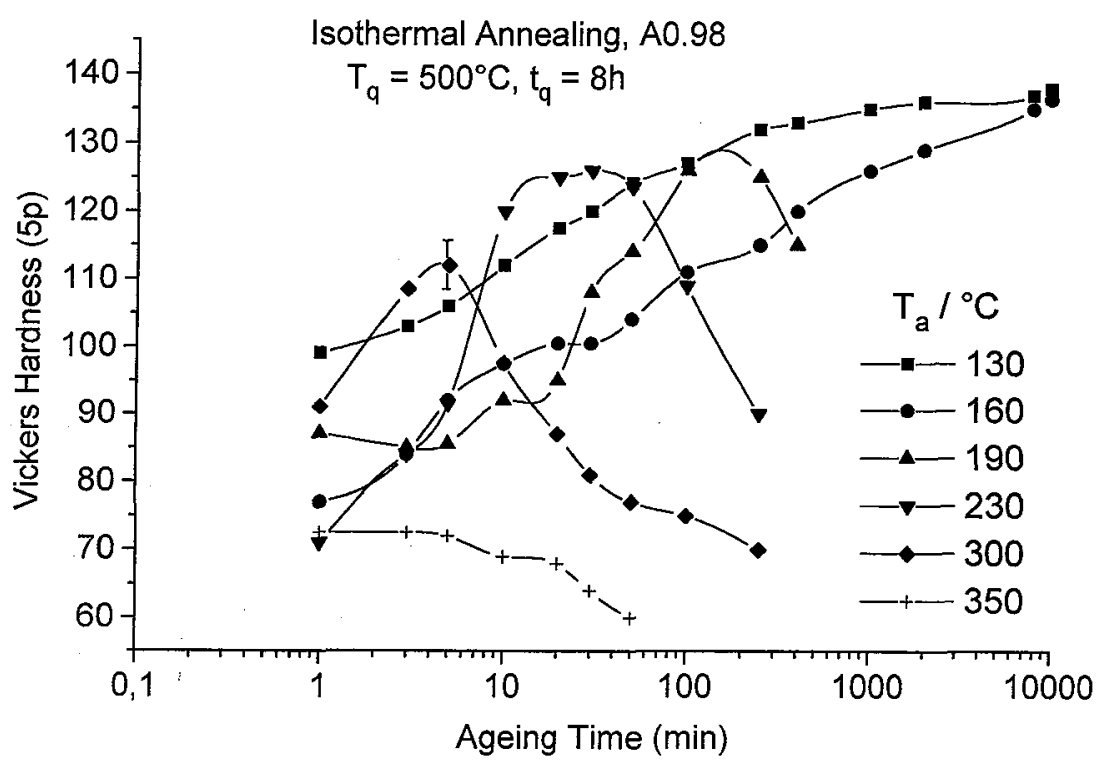

Fig.5: Vickers' hardness after isochronal annealing of AlCuMg alloys

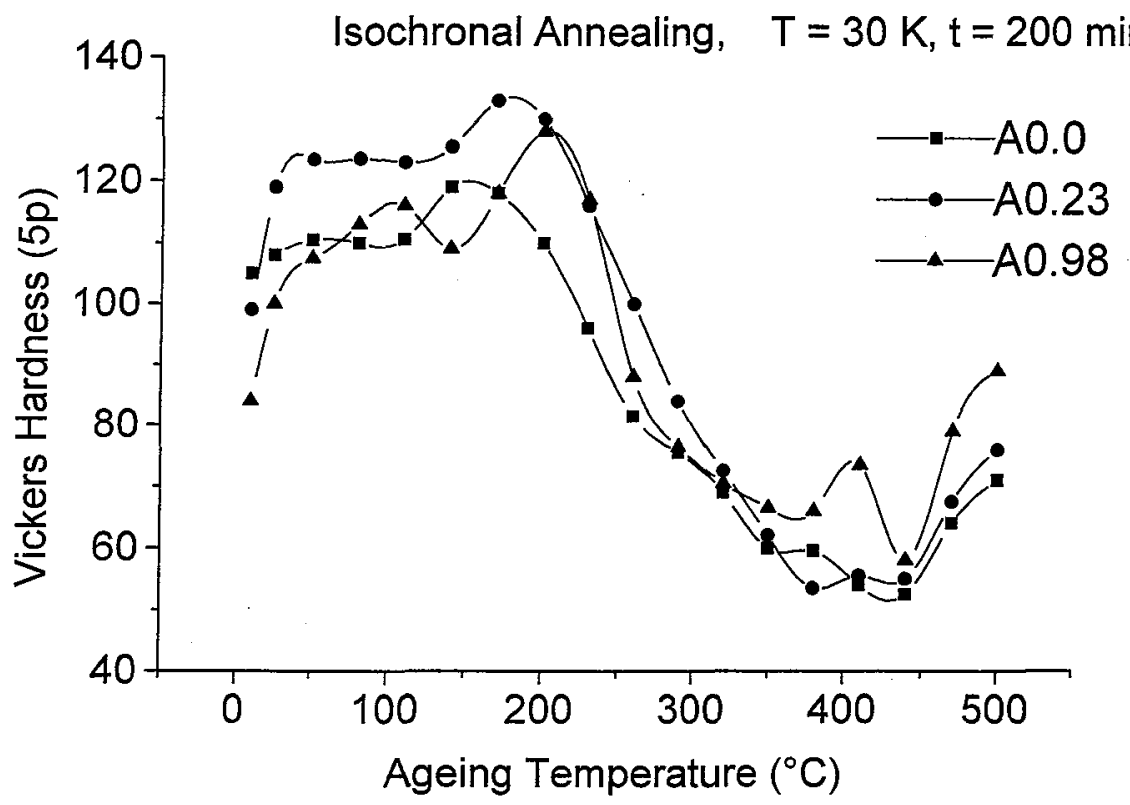


Fig.6: Positron-lifetime measurements of AlCuMg alloys after water quenching and isochronal heating, $t_{a}=200 \mathrm{~min}$ in steps of $30 \mathrm{~K}$

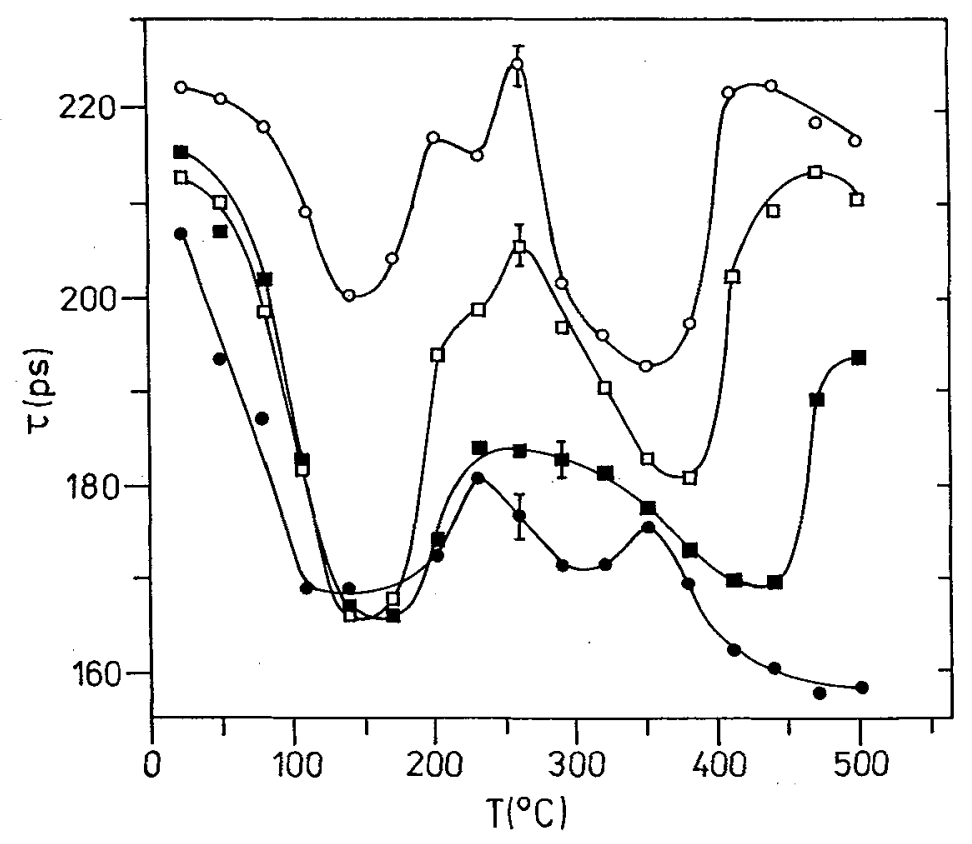

- AlCu 4.5

- AlCu 4.5Mg0.56

- AlCu $4.5 \mathrm{Mg} 0.23$

- AlCu 4.5 Mg0.98

Fig.7: Evolution of the mean diameter and particle density

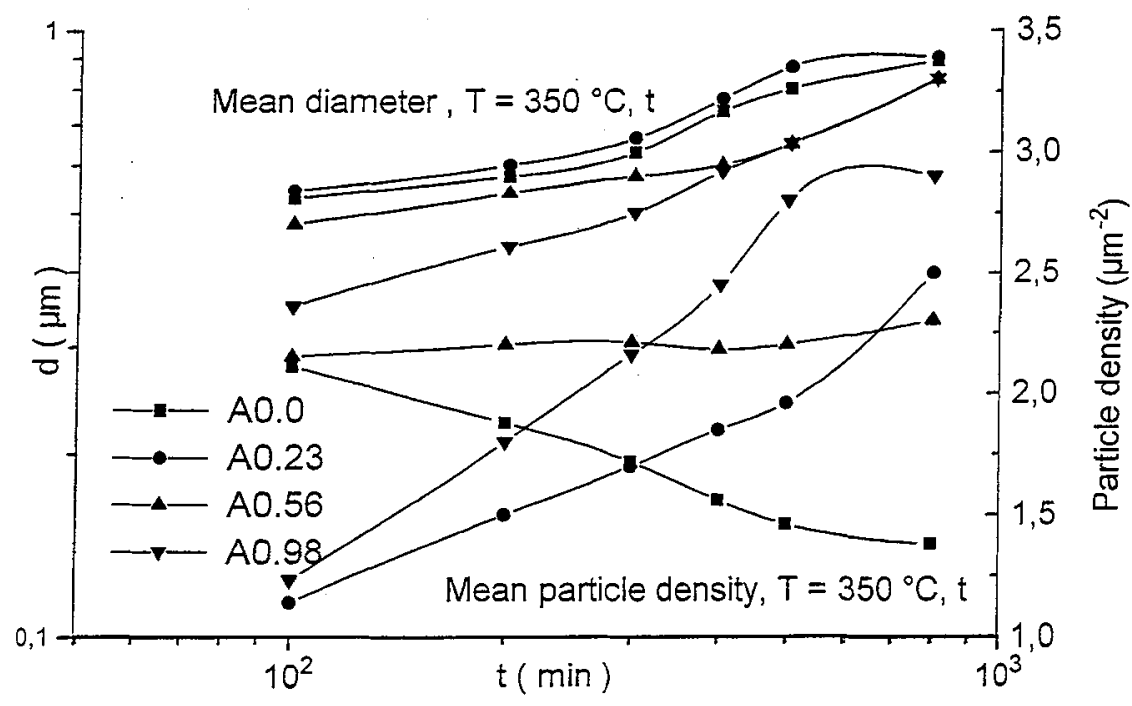

